\title{
Efeitos do acordo entre o Mercosul e a União Européia sobre os mercados de grãos
}

\author{
Augusto M. Alvim ${ }^{1}$ \\ Paulo D. Waquil ${ }^{2}$
}

Resumo: Este estudo busca mensurar os efeitos do acordo entre o Mercosul e a União Européia (UE) sobre a produção, consumo e fluxos comerciais de arroz, milho, soja e trigo nas diversas regiões analisadas. Para avaliar os efeitos deste acordo utilizamos um modelo de alocação espacial apresentado como um Problema de Complementaridade Mista (PCM). Como resultado, o presente estudo identifica as variações no Excedente do Produtor (EP) nos cenários Mercosul-UE e Mercosul-UE ampliada considerando a eliminação das barreiras tarifárias e/ou subsídios. Em termos gerais, os maiores ganhos para os produtores de grãos dos países do Mercosul ocorrem no cenário Mercosul-UE com eliminação dos subsídios por parte dos países da UE. No entanto, salienta-se que, embora os ganhos totais para os países do Mercosul sejam positivos, o setor tritícola apresenta perdas significativas neste cenário.

Palavras-chave: Mercosul, integração regional, grãos.

Classificação JEL: Q17

${ }^{1}$ Doutor em Economia. Professor da Faculdade de Administração, Contábeis e Economia (FACE) da Pontifícia Universidade Católica do Rio Grande do Sul (PUCRS).

augusto.alvim@pucrs.br

${ }^{2}$ Doutor em Economia Agrícola. Professor do Departamento de Economia (DECON) e dos Programas de Pós-Graduação em Desenvolvimento Rural (PGDR) e Agronegócios (PPGAN) da UFRGS. waquil@ufrgs.br 
Abstract: This study aims to measure the effects of an agreement between Mercosur and the European Union (EU) on production, consumption and trade flows of rice, maize, soybeans and wheat in several regions. To estimate the effects of this agreement we used a spatial allo-cation model presented as a Mixed Complementarity Problem. As a result, we identify the variations in Producer's Surplus for the scenarios Mercosur-EU and Mercosur-extended EU, considering the elimination of tariff barriers and/or subsidies. In general, the highest gains for grain producers in the Mercosur countries happen in the Mercosur-EU scenario with the elimination of subsidies by the European countries. However, we emphasize that total gains for the Mercosur countries are positive, but the wheat sector shows significant losses in this scenario.

Keywords: Mercosur, regional integration, grains.

JEL Code: Q17 - Agriculture in International Trade

\section{Introdução}

Nos últimos anos, as negociações para a redução do protecionismo e a conseqüente liberalização do comércio agrícola têm aparecido como um dos principais pontos na agenda externa do governo brasileiro e dos demais países do Mercosul. Em termos gerais, o Brasil tem adotado uma postura de global trader, procurando articular diversos acordos comerciais, que consideram diferentes critérios de abrangência espacial, como o maior envolvimento nas negociações multilaterais e o fortalecimento dos acordos regionais e bilaterais. Uma das razões mais importantes para esta postura reside na necessidade de buscar mercados para atender a expansão dos níveis de produção agrícola do país. A ampliação e integração dos mercados é tida como capaz de impulsionar os fluxos comerciais entre os países envolvidos, e assim permitir maior dinamismo e crescimento das economias participantes. Pode também garantir o acesso a uma maior quantidade e variedade de produtos. No entanto, um dos aspectos fundamentais para que os resultados sejam positivos e relevantes para os países envolvidos no processo é a existência de complementaridade entre as economias participantes, o que poderá determinar maiores ganhos agregados. 
Entre os acordos negociados pelo Brasil, em conjunto com os demais membros do Mercosul, está o acordo com a União Européia (UE), acordo este que tem sido apontado por diversos pesquisadores brasileiros como o que apresenta um maior potencial de ganhos para os setores agrícolas dos países do Cone Sul. Por outro lado, também são salientadas as dificuldades para implementar este acordo, principalmente em vista da proteção auferida pelos agricultores europeus, imposta pela Política Agrícola Comum (PAC) da UE e das distorções geradas nos mercados de produtos agrícolas. A respeito das relações entre o Mercosul e a UE, a assinatura em 1996 do "Acordo-Quadro Inter-regional de Cooperação" deu início às negociações para a formação da "Associação Inter-regional" entre os dois grupos de países. Os objetivos traçados no acordo eram de aproximação e cooperação em todas as áreas. Desta forma, a intenção seria de reforçar a parceria política, de atividades de cooperação e a criação de uma zona de livre comércio, observando a sensibilidade de alguns produtos e respeitando o conjunto de regras e diretrizes junto à Organização Mundial do Comércio (OMC). Em 1999, foi criado o Comitê de Negociações Bi-regionais (CNB), com a finalidade de reorganizar as relações comerciais e aproximar os dois blocos. Diversas reuniões já foram realizadas, formalizando compromissos que já apresentaram melhorias em suas ofertas.

Contudo, a agricultura ainda é o setor mais crítico nas negociações. A situação torna-se mais complexa com a entrada de dez novos países na UE a partir de 2004. Além de envolver um número maior de países nas negociações, as diferenças estruturais e produtivas se acentuam. Atualmente, poucos estudos avaliam os ganhos ou perdas aos produtores agrícolas do Mercosul frente a estes novos cenários econômicos.

É neste contexto que se insere o presente artigo, tendo por objetivo analisar os efeitos do possível acordo entre o Mercosul e a UE sobre os mercados de grãos. Consideramos, para isto, as variações nos níveis de produção, consumo, fluxos comerciais e preços estimados em quatro cenários, que incluem (a) o acordo Mercosul-UE somente com a remoção das barreiras tarifárias, (b) o acordo com a UE ampliada somente com a remoção das barreiras tarifárias, (c) o acordo Mercosul-UE com a remoção das barreiras tarifárias e dos subsídios, e finalmente (d) o acordo com a UE ampliada com a remoção das barreiras tarifárias e dos subsídios. 
Analisamos os mercados de quatro produtos: arroz, milho, soja e trigo, que correspondem à maior parcela dos grãos produzidos e comercializados no mundo. A seguir, apresentamos alguns dados sobre os mercados destes grãos nas principais regiões produtoras. Após, a metodologia, com o modelo de equilíbrio parcial (problema de complementaridade mista) utilizado, os principais resultados encontrados referentes aos cenários simulados e as considerações finais do artigo.

\section{Os mercados de arroz, milho, soja e trigo nas principais regiões}

Nesta seção, apresentamos e discutimos as principais características de cada mercado de grãos, destacando os principais produtores, exportadores e importadores. Em seguida, apontamos as principais barreiras tarifárias e não-tarifárias, bem como a concessão de subsídios pelos países desenvolvidos. Mesmo que o interesse mais específico do artigo seja na relação entre o Mercosul e a UE, é necessário considerar outras regiões para caracterizar os mercados e elaborar o cenário básico. Assim, distribuímos os níveis de produção, consumo e fluxos comerciais de acordo com as regiões ${ }^{1}$ conforme consta no quadro a seguir.

Na Tabela 1 a seguir, verifica-se a quantidade produzida e consumida, expressa em milhares de toneladas, assim como as exportações líquidas (exportações menos importações) de cada produto por cada região considerada. Os dados correspondem às médias observadas no triênio 2001-2003, evitando distorções causadas por anos atípicos em regiões específicas.

\footnotetext{
${ }^{1}$ Os países do Mercosul foram considerados separadamente, a fim de permitir a análise dos efeitos dos cenários sobre cada país-membro. Apenas o Paraguai não foi analisado separadamente, sendo incluído juntamente com Outros Países da América do Sul (OAS).
} 
Quadro 1. Distribuição das regiões.

\begin{tabular}{|l|l|}
\hline 1. & Argentina \\
\hline 2. & Brasil \\
\hline 3. & Uruguai \\
\hline 4. & $\begin{array}{l}\text { Comunidade Andina de Nações (CAN), composta pela Bolívia, Colômbia, Equador, } \\
\text { Peru e Venezuela }\end{array}$ \\
\hline 5. & Outros Países da América do Sul (OAS) \\
\hline 6. & América do Norte (NAM) \\
\hline 7. & $\begin{array}{l}\text { União Européia (UE 15), composta pelos quinze membros que já integravam o } \\
\text { bloco até 2004: Alemanha, Áustria, Bélgica, Dinamarca, Espanha, Finlândia, França, } \\
\text { Grécia, Holanda, Irlanda, Itália, Luxemburgo, Portugal, Reino Unido e Suécia }\end{array}$ \\
\hline 8. & $\begin{array}{l}\text { Os dez novos integrantes da União Européia a partir de 2004 (UE 10): Chipre, } \\
\text { Eslováquia, Eslovênia, Estônia, Hungria, Letônia, Lituânia, Malta, Polônia e } \\
\text { República Tcheca }\end{array}$ \\
\hline 9. & China \\
\hline 10. & $\begin{array}{l}\text { Associação das Nações do Sudeste Asiático (ASEAN) tem como países-membros: } \\
\text { a Indonésia, a Malásia, as Filipinas, a Tailândia, Cingapura, o Vietnã, Laos, a } \\
\text { Camboja, a Mianmar e o Brunei }\end{array}$ \\
\hline 11. & $\begin{array}{l}\text { Acordo Preferencial de Comércio do Sul da Ásia (SAPTA) prevê uma cooperação } \\
\text { regional entre a Índia, Bangladesh, Butan, Maldivas, Nepal, Paquistão e Sri } \\
\text { Lanka }\end{array}$ \\
\hline 12. & Oriente Médio \\
\hline 13. & África \\
\hline 14. & $\begin{array}{l}\text { Resto do Mundo: inclui todos os demais países, não pertencentes às regiões ou } \\
\text { blocos acima }\end{array}$ \\
\hline
\end{tabular}

Fonte: organizado pelos autores. 
Efeitos do acordo entre o Mercosul e a União Européia sobre os mercados de grãos

\begin{tabular}{|c|c|c|c|c|c|c|c|c|c|c|c|c|c|c|c|}
\hline \multirow{4}{*}{ 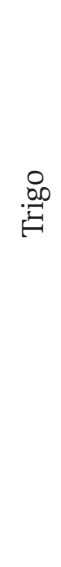 } & 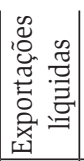 & $\begin{array}{l}\text { n. } \\
\stackrel{0}{0} \\
\widetilde{\sigma} \\
\infty\end{array}$ & $\begin{array}{l}\text { Fे } \\
\text { \&. } \\
\text { i. }\end{array}$ & ti & $\begin{array}{l}\stackrel{+}{~} \\
\text { Hु } \\
\text { +े }\end{array}$ & 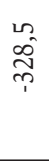 & $\begin{array}{l}\vec{\infty} \\
\overrightarrow{\&} \\
\vec{\infty}\end{array}$ & $\begin{array}{l}\vec{N} \\
\stackrel{\sim}{0} \\
+\end{array}$ & $\begin{array}{l}n \\
0 \\
0 \\
0 \\
i \\
i\end{array}$ & 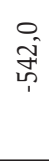 & 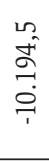 & $\begin{array}{l}\infty \\
\stackrel{\infty}{n} \\
= \\
\sim\end{array}$ & 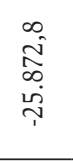 & \begin{tabular}{l}
$\mathcal{N}$ \\
\multirow{+}{0}{} \\
$\infty$ \\
$\infty$ \\
1
\end{tabular} & 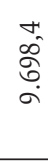 \\
\hline & 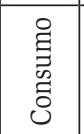 & $\begin{array}{l}0 \\
\text { in } \\
\text { in } \\
\text { in }\end{array}$ & 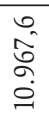 & $\begin{array}{l}\text { nn } \\
\text { o } \\
\text { ñ }\end{array}$ & $\begin{array}{l}\vec{f} \\
\text { बे } \\
\dot{+}\end{array}$ & $\begin{array}{l}\stackrel{\sim}{1} \\
\text { o } \\
\text { d̦ } \\
i\end{array}$ & 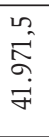 & 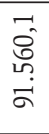 & 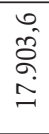 & $\begin{array}{l}\text { बे } \\
\text { ఫ్ర } \\
\dot{\Omega}\end{array}$ & $\begin{array}{l}\text { ڤ్ } \\
\stackrel{\text { సे}}{0}\end{array}$ & $\begin{array}{l}0 \\
0^{\circ} \\
\text { ñ. } \\
\infty\end{array}$ & 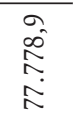 & 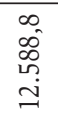 & $\begin{array}{l}\text { वे } \\
\text { ஸึ } \\
\text { ஸु. } \\
\text { ठ․ }\end{array}$ \\
\hline & 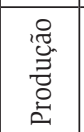 & $\begin{array}{l}\text { ने } \\
\text { Dे } \\
0 \\
\dot{+}\end{array}$ & 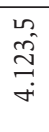 & ปี & 离 & $\begin{array}{l}\hat{\sim} \\
\stackrel{0}{0} \\
\stackrel{\sim}{\sim}\end{array}$ & 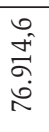 & $\begin{array}{l}\text { N } \\
\text { సే } \\
\text { ñ } \\
\text { ñ }\end{array}$ & 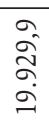 & $\begin{array}{l}2 \\
\hat{\alpha} \\
0 \\
\dot{\alpha}\end{array}$ & $\begin{array}{l}H \\
\sigma\end{array}$ & 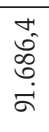 & $\begin{array}{l}\vec{\delta} \\
\stackrel{8}{~}\end{array}$ & $\begin{array}{l}0 \\
\text { Oे } \\
\stackrel{+}{+} \\
+\end{array}$ & 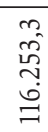 \\
\hline & 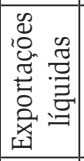 & 旾 & 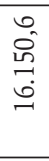 & $\begin{array}{l}0 \\
\infty \\
\infty\end{array}$ & $\begin{array}{l}\infty \\
\stackrel{0}{\Omega} \\
\stackrel{1}{1}\end{array}$ & 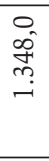 & 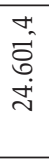 & $\begin{array}{l}\infty \\
\infty \\
0 \\
0 \\
\infty \\
1\end{array}$ & $\stackrel{m}{\stackrel{n}{+}}$ & 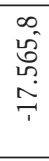 & $\begin{array}{l}0 \\
0 \\
0 \\
0 \\
\dot{1} \\
\dot{1}\end{array}$ & 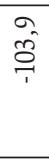 & 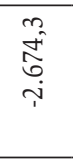 & $\tilde{n}_{\text {n̂ }}^{n}$ & 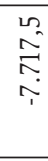 \\
\hline \multirow[t]{3}{*}{$\frac{\pi}{2}$} & 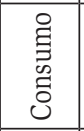 & 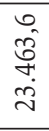 & 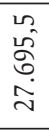 & $\stackrel{+}{\leftrightarrows}$ & $\begin{array}{l}\overrightarrow{+} \\
\vec{a} \\
\vec{i}\end{array}$ & 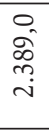 & 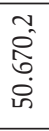 & $\begin{array}{l}\infty \\
\infty \\
\sigma \\
\infty \\
\infty\end{array}$ & \begin{tabular}{l}
+ \\
s \\
\multirow{2}{*}{}
\end{tabular} & $\begin{array}{l}\vec{f} \\
\vec{d} \\
\dot{n} \\
m\end{array}$ & $\begin{array}{l}\text { g. } \\
\text { di } \\
\text { in }\end{array}$ & 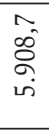 & $\begin{array}{l}\sigma \\
\text { जे } \\
\text { क } \\
\infty \\
i\end{array}$ & 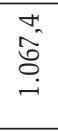 & $\hat{\tilde{A}}$ \\
\hline & 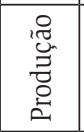 & 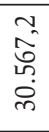 & 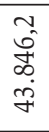 & $\begin{array}{r}\stackrel{+}{a} \\
\text { an }\end{array}$ & 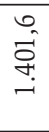 & $\begin{array}{l}\vec{n} \\
\hat{n} \\
\dot{n}\end{array}$ & 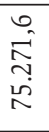 & $\begin{array}{l}\text { के } \\
\text { ळे }\end{array}$ & $\vec{i}$ & $\begin{array}{l}n \\
\infty \\
\infty \\
n \\
n \\
0 \\
-1\end{array}$ & 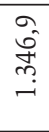 & $\begin{array}{l}\infty \\
\delta^{0} \\
\infty \\
\text { in }\end{array}$ & $\hat{\bar{\nabla}}$ & 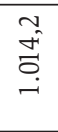 & 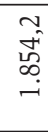 \\
\hline & 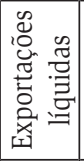 & 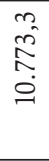 & \begin{tabular}{l} 
un \\
\multirow{0}{0}{} \\
$\stackrel{1}{1}$
\end{tabular} & $\begin{array}{l}0 \\
\text { ते }\end{array}$ & $\begin{array}{l}\text { aे } \\
\text { त् } \\
\dot{p}\end{array}$ & 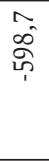 & 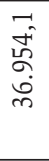 & $\begin{array}{l}\text { ڤે } \\
\text { ஸे } \\
\hat{\gamma}\end{array}$ & $\begin{array}{l}+ \\
\infty \\
0 \\
0 \\
0 \\
-\end{array}$ & 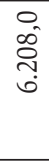 & $\begin{array}{l}\vec{r} \\
\dot{n} \\
\infty \\
\infty \\
\dot{p}\end{array}$ & 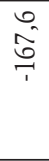 & 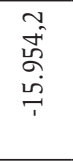 & 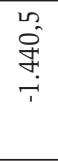 & 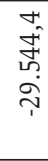 \\
\hline \multirow[t]{3}{*}{ 号 } & $\begin{array}{l}\stackrel{0}{\Xi} \\
\Xi \\
0 \\
0 \\
0\end{array}$ & $\begin{array}{l}\hat{\sigma} \\
\tilde{5} \\
\dot{\sigma}\end{array}$ & 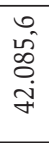 & ָָ & $\begin{array}{l}\stackrel{7}{0} \\
\vec{\sigma} \\
\stackrel{0}{0} \\
\sigma\end{array}$ & 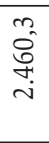 & 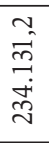 & \begin{tabular}{l} 
un \\
ô \\
\multirow{3}{0}{} \\
$\dot{m}$
\end{tabular} & $\begin{array}{l}m \\
\stackrel{m}{2} \\
\infty \\
\infty\end{array}$ & 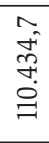 & $\begin{array}{l}\infty \\
\infty \\
\infty \\
\infty \\
\infty \\
\sim \\
\sim\end{array}$ & 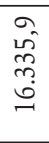 & \begin{tabular}{l}
$\sim$ \\
\multirow{\sigma}{\sigma}{} \\
$\infty$ \\
$\sim$
\end{tabular} & 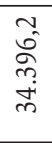 & $\begin{array}{l}\text { nn } \\
\hat{N} \\
\hat{N} \\
\hat{R}\end{array}$ \\
\hline & 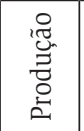 & 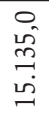 & $\begin{array}{l}\text { フू } \\
\text { જે } \\
\infty \\
\dot{F}\end{array}$ & $\begin{array}{l}0 \\
\text { D্ं }\end{array}$ & $\begin{array}{l}\text { N } \\
\text { ff } \\
\text { m } \\
\text { in }\end{array}$ & 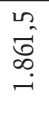 & 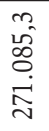 & $\begin{array}{l}n \\
\text { ñ } \\
\infty \\
\dot{n} \\
\dot{n}\end{array}$ & $\underset{\tilde{N}}{\tilde{N}}$ & \begin{tabular}{l}
0 \\
\multirow{J}{J}{} \\
$\stackrel{0}{0}$ \\
$=$
\end{tabular} & 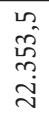 & 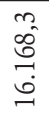 & 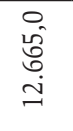 & $\begin{array}{l}\hat{n} \\
\text { जू } \\
\text { iे } \\
\text { nె }\end{array}$ & $\begin{array}{l}\stackrel{0}{n} \\
\stackrel{n}{n} \\
\stackrel{+}{F}\end{array}$ \\
\hline & 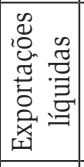 & $\overrightarrow{\widetilde{d}}$ & $\begin{array}{l}0 \\
\text { î } \\
\text { న̂ }\end{array}$ & $\begin{array}{l}\infty \\
\text { बi }\end{array}$ & $\begin{array}{l}0 \\
0 \\
\infty \\
\infty\end{array}$ & 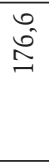 & 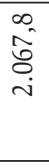 & 胥 & $\vec{\sim}$ & 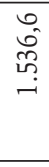 & $\begin{array}{l}\text { है } \\
\text { ஸे } \\
\infty\end{array}$ & $\begin{array}{l}0 \\
0 \\
n \\
0 \\
0 \\
+ \\
+\end{array}$ & $\begin{array}{l}0 \\
\infty \\
0 \\
0 \\
r\end{array}$ & $\begin{array}{l}\text { ñ } \\
\text { ôे } \\
\text { مे } \\
\text { in }\end{array}$ & 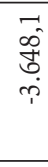 \\
\hline \multirow[t]{3}{*}{ 思 } & 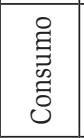 & $\begin{array}{l}m \\
\text { ô } \\
\text { ñ }\end{array}$ & $\begin{array}{l}0 \\
\hat{i} \\
\tilde{\sigma} \\
\stackrel{\Xi}{=}\end{array}$ & $\underset{\substack{+\infty \\
\infty}}{\infty}$ & $\begin{array}{l}\text { r } \\
\text { On } \\
\infty \\
0 \\
0\end{array}$ & $\begin{array}{l}\text { un } \\
\text { on } \\
\text { ñ }\end{array}$ & $\begin{array}{l}0 \\
0 \\
0 \\
0 \\
n \\
n\end{array}$ & $\begin{array}{l}\infty \\
0 \\
\hat{N} \\
m \\
m \\
m\end{array}$ & 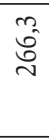 & 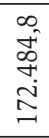 & $\begin{array}{l}n \\
\infty \\
o \\
o \\
o \\
\dot{+} \\
\dot{+}\end{array}$ & $\begin{array}{l}0 \\
\infty \\
\infty \\
\infty \\
\mathbb{I} \\
\end{array}$ & 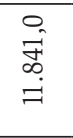 & 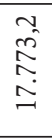 & $\begin{array}{l}\hat{\sigma} \\
\tilde{\delta} \\
\hat{\sigma} \\
\tilde{\sim}\end{array}$ \\
\hline & 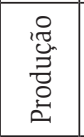 & $\vec{n}$ & $\begin{array}{l}0 \\
0 \\
0 \\
0 \\
0 \\
0\end{array}$ & $\tilde{n}_{0}^{\sim}$ & \begin{tabular}{l}
+ \\
\multirow{2}{*}{} \\
\multirow{\jmath}{0}{}
\end{tabular} & $\begin{array}{l}\vec{n} \\
\tilde{n}\end{array}$ & $\begin{array}{l}\infty \\
2 \\
0 \\
0 \\
0\end{array}$ & 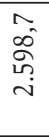 & $\tilde{\sigma}$ & $\begin{array}{l}\vec{H} \\
\vec{J} \\
\dot{J} \\
\stackrel{+}{J}\end{array}$ & 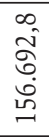 & 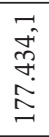 & $\begin{array}{l}\text { un } \\
\text { I } \\
\sim \\
\infty\end{array}$ & 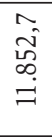 & 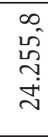 \\
\hline & 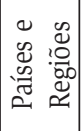 & 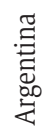 & 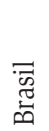 & 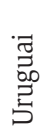 & 㤂 & 赵 & $\sum_{Z}$ & $\begin{array}{l}\text { 兄 } \\
\text { 舄 }\end{array}$ & $\begin{array}{l}\text { 으 } \\
\text { 빔 }\end{array}$ & 节 & $\begin{array}{l}\text { 茊 } \\
\text { 查 }\end{array}$ & $\underset{⿱ 亡 心}{\rightleftarrows}$ & 壳 : & 暯 & 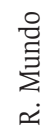 \\
\hline
\end{tabular}

RER, Rio de Janeiro, vol. 43, no 04, p. 703-723, out/dez 2005 - Impressa em dezembro 2005 
Considerando inicialmente o mercado de arroz, salientamos o continente asiático, tendo como principais regiões produtoras a SAPTA, a China e a ASEAN que juntas representam mais de $87 \%$ da produção mundial. Estas produzem, respectivamente, 177,4; 174,0 e 156,7 milhões de toneladas. Entretanto, grande parte da produção é consumida nos seus próprios mercados, de modo que nem sempre os maiores produtores são também os maiores exportadores. Como principais regiões exportadoras de arroz aparecem a ASEAN, SAPTA e NAM com exportações líquidas de 8,6, 4,6 e 2,0 milhões de toneladas. Dentro da ASEAN os principais países exportadores são a Tailândia e o Vietnã. Já na SAPTA destacamos como exportadores a Índia e o Paquistão. Por fim, na região da NAM o único país exportador são os EUA, já que o Canadá e o México são importadores de arroz. No grupo dos importadores de arroz, os países da África e do Oriente Médio que, conjuntamente, adquirem $41,8 \%$ do arroz que é comercializado no mundo. Também os países da UE ampliada (25) são importadores líquidos de arroz, em quantidades que atingem 1.101,2 mil toneladas. Considerando apenas os países do Mercosul, existem excedentes de arroz da ordem de 185,9 mil de toneladas. Os principais responsáveis pela exportação de arroz no bloco são a Argentina e o Uruguai, exportando para o Brasil e outros países de fora do bloco, conjuntamente, 937,9 mil toneladas. Na média do triênio considerado, o Brasil ainda aparecia como importador, apesar de nos últimos anos vir apresentando incremento na produção e chegando, em 2004, a gerar um excedente exportável.

No mercado do milho, os maiores produtores do mundo são os países da América do Norte (NAM), China, Brasil e UE 15 que produzem, conjuntamente, cerca de 463,5 milhões de toneladas de milho, com uma participação de $74,7 \%$ do total produzido no mundo. Considerando a participação de cada região, separadamente, os países da América do Norte (NAM), a China, o Brasil e a UE 15 possuem, respectivamente, parcelas do total produzido de $43,7 \%$, 18,79\%, 6,75\% e 5,46\%. Os EUA aparecem como o maior produtor de milho, com uma produção total de 256,9 milhões de toneladas de milho seguido pela China com uma produção de 116,6 milhões de toneladas. Em termos de comércio agrícola internacional, os maiores exportadores de milho são a NAM, China e Argentina. Deste grupo de países os maiores exportadores líquidos (exportações menos importações) são os EUA e a Argentina, pois a China apesar de ser uma 
grande exportadora, também importa quantidades significativas de milho. No caso específico da UE 15, observa-se que existe um fluxo de comércio intra-bloco significativo, contudo, quando observado o resultado líquido, a participação no comércio mundial é reduzida, classificando a UE 15 como uma região importadora. Os principais países importadores de milho são pertencentes à região chamada de "resto do mundo", Oriente Médio, ASEAN e CAN. Neste grupo chamado de "resto do mundo" o Japão e a Coréia do Sul são os principais importadores. Considerando apenas os países do Mercosul, apesar do Brasil e Uruguai surgirem como importadores, observamos que há um excedente de 10,6 milhões de toneladas de milho que são exportados para outros países.

O terceiro mercado a ser analisado é o da soja. Neste mercado, observamos como principais produtores a região NAM (essencialmente os EUA), o Brasil, a Argentina e a China. Estas regiões possuem uma produção média no período de 75,3 (41,3\%), 43,8 (24,1\%), 30,6 (16.8\%) e 16,1 milhões de toneladas $(8,9 \%)$, respectivamente. Conjuntamente estas regiões produzem $91,1 \%$ da produção mundial de soja. Destas regiões a NAM, o Brasil e a Argentina detêm mais de 93,2\% das exportações mundiais, com exportações líquidas de 24,6, 16,2 e 7,1 milhões de toneladas, respectivamente. Por outro lado, as importações de soja são menos concentradas, sendo distribuídas entre os países da UE 15, China, NAM, ASEAN e Oriente Médio. Atualmente, os principais países importadores são a UE 15 e a China que, conjuntamente, importam cerca de 63,0\% da soja no mundo. A região do "resto do mundo" também apresentou como importadora líquida chegando a importar no período cerca de 7,7 milhões de toneladas. No caso específico dos países do Mercosul, o bloco é um grande exportador líquido, atingindo 23,3 milhões de toneladas para outros mercados. A UE, mesmo ampliada com a incorporação de mais dez países, mantém a necessidade de importar, anualmente, 18,2 milhões de toneladas, o que aponta para a complementaridade das atividades produtivas entre os blocos.

Por fim, no mercado do trigo os principais produtores são os países da UE 15, SAPTA, China e NAM, que apresentam uma produção de 95,8, 91,7, 90,1 e 76,9 milhões de toneladas, respectivamente. Destas regiões, destacamos como maiores exportadores líquidos a NAM (EUA e o Canadá), os países da UE 15 e a Argentina que vendem 34,9, 4,3 e 
8,9 milhões de toneladas, respectivamente. Conjuntamente, estes países exportam cerca de $70 \%$ das exportações mundiais. Já os principais importadores são os países do Oriente Médio, da UE 15 (notamos que a UE aparece como exportadora e importadora, em função dos fluxos intra-regionais), da ASEAN, da África e o Brasil. Estas regiões, em conjunto, englobam 68,3\% das importações de trigo no mundo. Por fim no caso específico dos países do Mercosul existe um excedente exportável de apenas 1,9 milhões de toneladas, em função de que o maior comprador do trigo produzido na Argentina é o Brasil, mais uma vez reforçando a importância dos fluxos intra-regionais. Por outro lado, a UE ampliada (25 países) possui também excedentes exportáveis de 6,3 milhões de toneladas.

Considerando todos os grãos acima analisados, observamos que existe complementaridade entre os fluxos comerciais dos países do Mercosul e os dos países da UE ampliada, com exceção do trigo, onde ambos os blocos são exportadores. Para o caso do arroz, do milho e da soja existe possibilidade de exportar parte dos excedentes do Mercosul para o mercado europeu. Contudo, a realização destas expectativas irá depender basicamente das negociações em torno das barreiras tarifárias e dos subsídios aplicados pelas regiões mais desenvolvidas.

De uma maneira geral, no mercado de grãos as principais barreiras aplicadas pelos países podem ser divididas em dois grupos: tarifas e quotas-tarifárias. No caso do arroz e do milho, a UE aplica quotas-tarifárias aos produtos importados de outros mercados. Outros países considerados no estudo impõem tarifas ad valorem nestes mercados. Além destas barreiras aplicadas, os EUA e os países da UE subsidiam a produção de arroz e milho. No caso dos EUA esta estratégia permite aumentar a competitividade das suas exportações no mercado internacional. Para a UE, os subsídios aumentam a renda dos agricultores europeus, diminuindo o impacto negativo dos produtos importados sobre a sua renda. Já nos mercados de soja e trigo existem menores distorções em termos de barreiras tarifárias. A UE 15 não aplica tarifas sobre a soja e o trigo originários de fora do bloco. Também os países da NAM aplicam tarifas médias mais baixas e de pequena relevância, na medida em que o bloco é um dos maiores exportadores de soja e trigo. Com relação aos demais países analisados a principal barreira a produtos importados é a tarifa 
ad valorem. Porém, no caso dos subsídios existem algumas diferenças entre estas regiões. Os países da NAM (principalmente os EUA) subsidiam tanto a produção de soja como de trigo. Contudo, no caso da UE estes subsídios são concedidos apenas para a produção de trigo.

Na próxima seção são apresentados os principais aspectos relativos à metodologia que permite projetar o cenário-base e simular alguns cenários ligados ao acordo Mercosul-UE. Este modelo permite estimar os ganhos e as perdas, medido em termos de variações no Excedente do Produtor (EP), em cada cenário, nas diversas regiões consideradas neste trabalho.

\section{O problema de complementaridade mista}

O modelo de otimização descrito nesta seção utiliza uma formulação apresentada na forma de um Problema de Complementaridade Mista (PCM), conforme proposto por Thore (1992), Rutheford (1995) e Bishop, Nicholson e Pratt (2001) e já utilizado por Alvim (2003) e Alvim e Waquil (2004). É um modelo de equilíbrio espacial que pressupõe produtos homogêneos e considera a tecnologia, as preferências e o crescimento populacional como variáveis exógenas. O Problema de Complementaridade Mista (PCM) consiste em um sistema de equações simultâneas (lineares ou não), apresentadas na forma de desigualdades, as quais são derivadas a partir das funções de oferta e demanda dos produtos considerados em cada uma das regiões analisadas. O PCM é equivalente às condições de Kuhn-Tucker do problema de maximização da função Net Social Payoff 2 (NSP), condições estas que são necessárias e suficientes para atingir um ponto de máximo do valor da função NSP, o que por sua vez implica na obtenção do equilíbrio em todos os mercados e em todas as regiões. Entretanto, o PCM tem a vantagem de permitir a incorporação de tarifas, quotas-tarifárias e subsídios com mais facilidade ao modelo.

\footnotetext{
${ }^{2}$ Samuelson (1952) mostrou que o equilíbrio de mercado pode ser alcançado a partir da maximização da função de Net Social Payoff (NSP), obtida a partir da soma dos excedentes dos produtores e dos consumidores.
} 
Quadro 2. Variáveis utilizadas no modelo

\begin{tabular}{|l|l|}
\hline $\mathbf{q}_{\mathrm{j}}^{\mathrm{d}}$ & quantidade demandada na região $\mathrm{j}$ \\
\hline $\mathbf{q}_{\mathrm{i}}^{\mathrm{s}}$ & quantidade ofertada na região i \\
\hline $\mathbf{X}_{\mathrm{i}, \mathrm{j}}$ & fluxo de comércio entre a região i e a região $\mathrm{j}$ \\
\hline $\mathrm{t}_{\mathrm{i}, \mathrm{j}}$ & custo de transporte da região i para a região $\mathrm{j}$ \\
\hline $\operatorname{tar}_{i, j}$ & tarifa imposta sobre o produto originário da região i na região $\mathrm{j}$ \\
\hline$q r_{i, j}$ & tarifa aplicada quando o fluxo exceder a quota tarifária $\mathrm{Q}_{\mathrm{i}, \mathrm{j}}$ \\
\hline $\boldsymbol{\varphi}_{\mathrm{i}}$ & multiplicador de Lagrange: preço-sombra na região produtora $\mathrm{i}$ \\
\hline$\lambda_{\mathrm{j}}$ & multiplicador de Lagrange: preço-sombra na região consumidora $\mathrm{j}$ \\
\hline
\end{tabular}

Fonte: organizado pelos autores.

O conjunto das equações apresentadas abaixo corresponde ao PCM e representa as condições que permitem obter os preços (preços-sombra), as quantidades consumidas e produzidas e os fluxos comerciais entre as regiões, levando em consideração as tarifas e quotas-tarifárias implementadas nos mercados.

$$
\begin{aligned}
& \varphi_{\mathrm{i}} \geq 0, \quad\left(\sum_{\mathrm{j}}^{\mathrm{j}} \mathrm{x}_{\mathrm{i}, \mathrm{j}}-\mathrm{q}_{\mathrm{i}}^{\mathrm{s}}\right) \cdot \varphi_{\mathrm{i}}=0, \forall \mathrm{i}, \mathrm{j} \\
& \lambda_{\mathrm{j}} \geq 0, \quad\left(\mathrm{q}_{\mathrm{j}}^{\mathrm{d}}-\sum_{\mathrm{i}}^{\mathrm{I}} \mathrm{X}_{\mathrm{i}, \mathrm{j}}\right) \cdot \lambda_{\mathrm{j}}=0, \forall \mathrm{i}, \mathrm{j} \\
& \mathrm{X}_{\mathrm{i}, \mathrm{j}} \geq 0, \quad\left(\lambda_{j}-\left(\varphi_{i}+t_{i, j}\right) \cdot\left(1+\operatorname{tar}_{i, j}+q r_{i, j}\right)\right) X_{i, j}=0, \forall i, j \\
& q r_{i, j} \geq 0, \quad\left(Q_{i, j}-X_{i, j}\right) \cdot q r_{i, j}=0, \forall i, j
\end{aligned}
$$

Considerando a primeira equação, observa-se que $\varphi_{1}$ é uma variável complementar à expressão que restringe a soma das exportações da i-ésima região ao total produzido naquela região i, e representa o preço-sombra na região produtora i. Da mesma forma, a segunda equação apresenta uma variável $\lambda_{j}$ que é complementar à expressão que restringe a soma 
das importações da j-ésima região ao total consumido naquela região j, e representa o preço-sombra na região consumidora j. A combinação das equações (3) e (4) determina que, se os fluxos comerciais de uma determinada região i para a região $\mathrm{j}$ forem maiores do que zero, porém inferiores à quota estabelecida pela região $\mathrm{j}\left(\mathrm{Q}_{\mathrm{i}, \mathrm{j}}\right)$, o preço do produto na região consumidora j será resultado da combinação do preço na região produtora i, dos custos de transporte da região i para j e da tarifa imposta sobre as importações originárias da região i. Por outro lado, se as importações da região j forem iguais à quota determinada para a região, então o preço do produto na região j dependerá também da tarifa excedente $\mathrm{qr}_{\mathrm{i}, \text {, }}$ , além do preço, dos custos de transportes e das tarifas de importação.

Os preços dos produtos, quantidades consumidas e ofertadas para a implementação do modelo foram obtidos através do banco de dados da FAO, utilizando a média de três anos (2001-2003). A justificativa para utilizar a média de três anos é a redução dos efeitos de alterações eventuais nos níveis destas variáveis, causadas por choques ou mudanças abruptas na economia, por eventos climáticos ou por outras variáveis que afetam a produção, consumo e preços ocasionalmente. Para implementar o modelo também são necessárias as elasticidades-preço de oferta e de demanda ${ }^{3}$, as quais foram obtidas a partir do trabalho de Sullivan et al. (1992). Os custos totais de transporte entre as regiões em estudo foram calculados com base no custo de transporte de uma tonelada de soja via marítima (US\$/milhas marítimas), obtido a partir do USDA (2002) e das distâncias entre os países/regiões em estudo (milhas marítimas). Já as tarifas ad valorem sobre as importações foram obtidas a partir do banco de dados da UNCTAD. Como não existe uma tarifa comum em todos os países pertencentes às regiões definidas na área de estudo, foram utilizadas as tarifas médias dos países importadores dos blocos ou regiões escolhidas.

\section{Resultados}

A área de estudo abrange o mercado mundial de arroz, milho, soja e trigo, incluindo os principais países produtores, exportadores e im-

\footnotetext{
${ }^{3}$ As elasticidades são necessárias para definir as funções de oferta e demanda que geram as equações (1) e (2).
} 
portadores. Apesar do foco deste estudo ser o acordo entre os países do Mercosul e da UE, são também incluídas as regiões com relevância em termos de produção ou comércio, como também as regiões que possuem afinidade comercial com os países do Mercosul, conforme definido na seção 2. A partir da definição da área de estudo calibramos o cenário-base buscando aproximar as estimativas de produção, consumo e preços dos grãos, com as médias observadas no triênio. No cenário-base foram incluídas todas as barreiras tarifárias e os subsídios concedidos pelos países/regiões considerados.

A partir do cenário-base foram definidos quatro cenários alternativos considerando as negociações entre o Mercosul e a UE. São eles: Mercosul-UE e Mercosul-UE ampliada (sem a eliminação de subsídios por parte da UE 15); e Mercosul-UE e Mercosul-UE ampliada (com a eliminação dos subsídios por parte da UE 15). Nas Tabelas 2 e 3 a seguir, são apresentadas as variações nos excedentes do produtor $(\Delta \mathrm{EP})$ para cada produto e cenário alternativo, sempre em relação ao cenário-base. A Tabela 2 apresenta as variações percentuais nos excedentes dos produtores, enquanto a Tabela 3 apresenta as variações dos excedentes do produtor em milhões de dólares para cada produto e cenário analisado. 


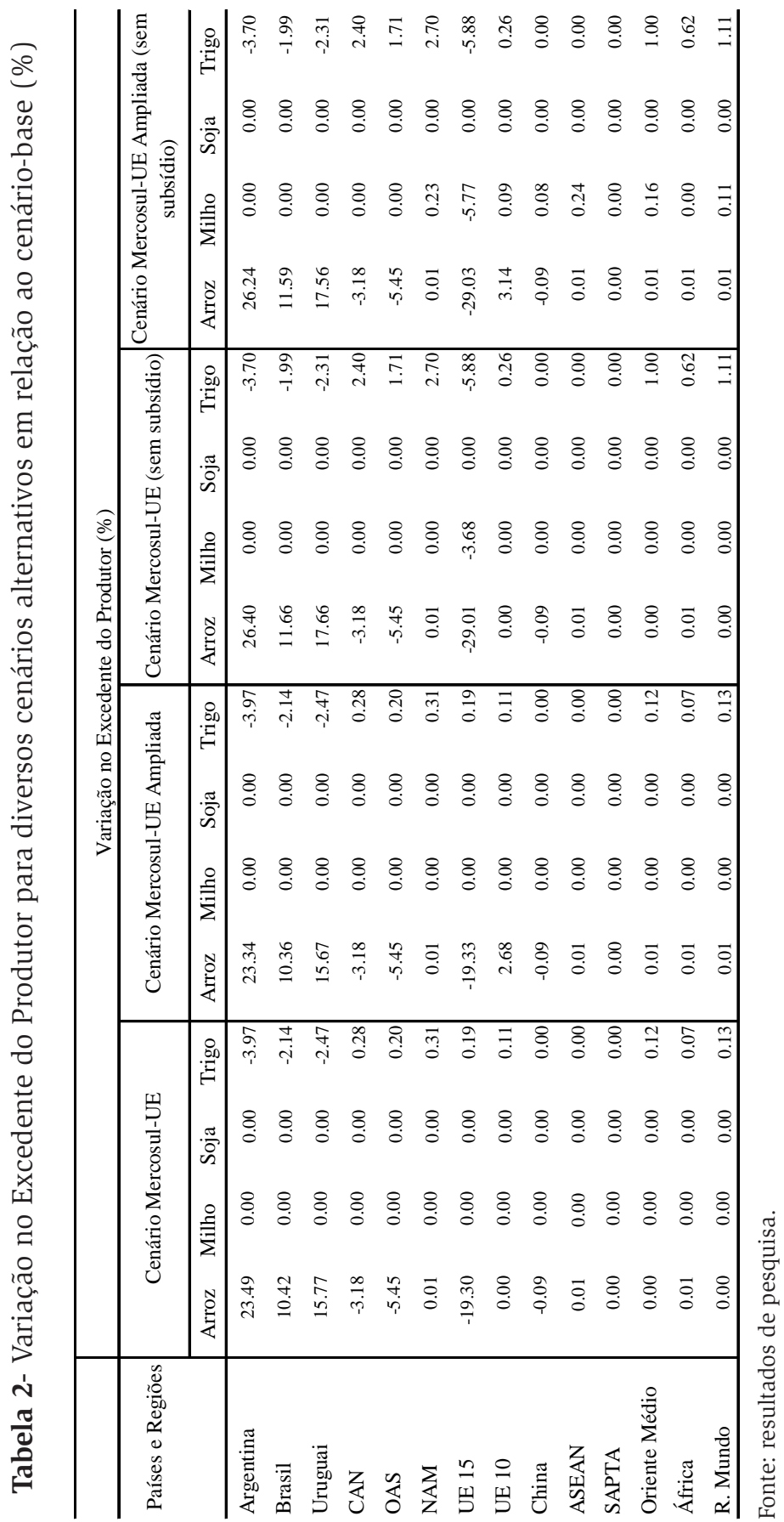




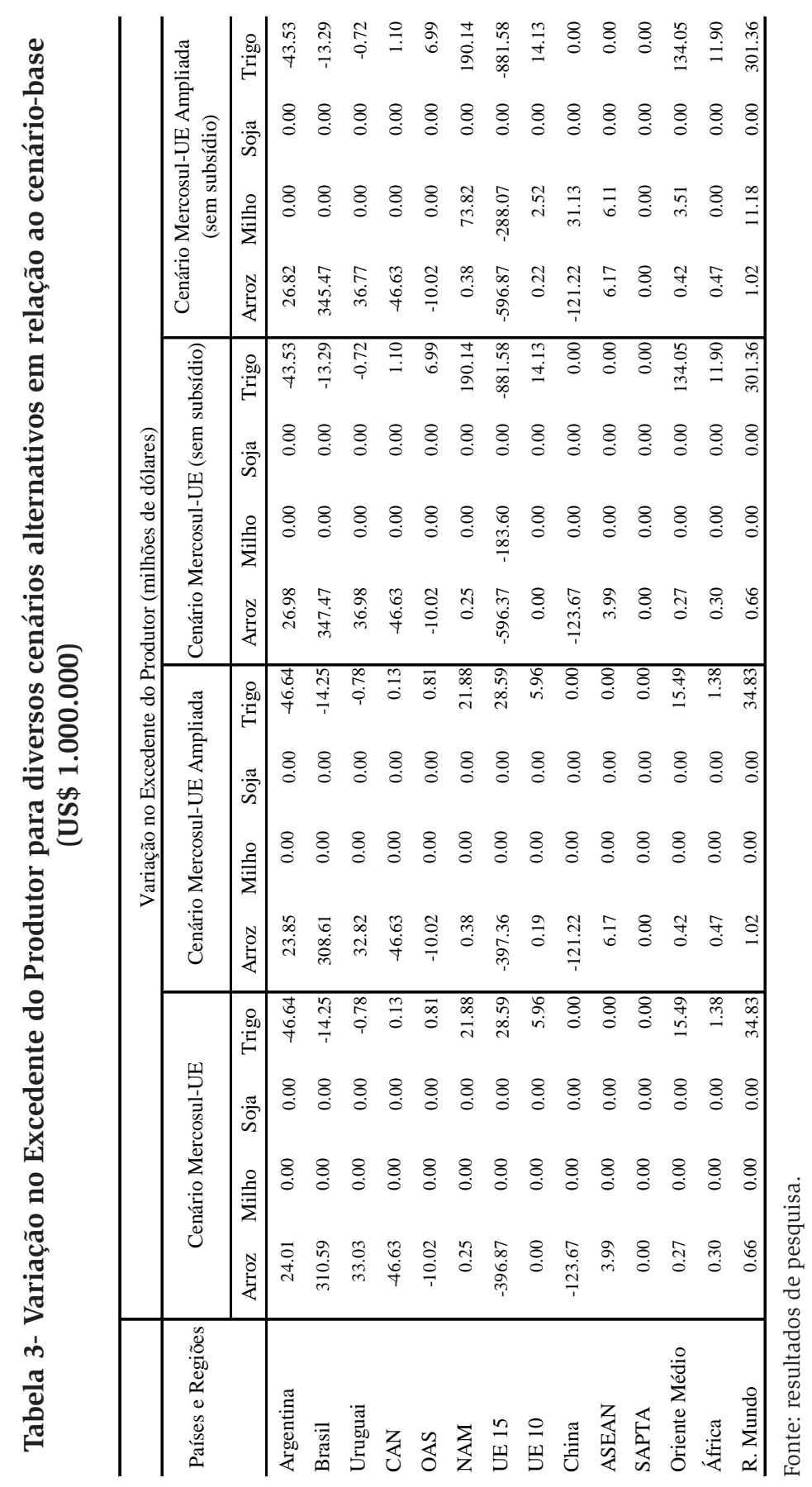


No caso do arroz, existem ganhos para os países do Mercosul (Argentina, Brasil e Uruguai) em todos os cenários simulados. Com relação ao acordo Mercosul-UE, mantendo os subsídios europeus para a produção de grãos, em termos relativos os principais países ganhadores são a Argentina, o Brasil e o Uruguai, com acréscimos nos excedentes dos produtores de $23,5 \%, 10,4 \%$ e $15,8 \%$. Já as regiões perdedoras são a CAN, OAS, e UE 15, com decréscimos nos excedentes dos produtores de $3,2 \%, 5,5 \%$ e $19,3 \%$, respectivamente. Neste cenário, o processo de criação de comércio propicia um aumento das exportações da Argentina e do Uruguai, redirecionando as exportações de arroz para o mercado europeu. Em termos absolutos o Brasil tem um grande ganho neste cenário, chegando a superar US\$ 310 milhões.

No segundo cenário, Mercosul-UE ampliada (sem a eliminação dos subsídios), as variações no excedente do produtor são muito parecidas com o cenário anterior. A diferença fundamental está relacionada com a inclusão dos dez novos países na UE, possibilitando um pequeno ganho $(2,7 \%)$ para estes novos integrantes do bloco. Em ambos cenários, embora não exista a eliminação dos subsídios, os produtores de arroz no Brasil têm ganhos em função do redirecionamento das exportações argentinas e uruguaias para o mercado europeu, chegando a se tornar também um exportador do produto. As exportações brasileiras alcançam cerca de 604 mil toneladas anuais, enquanto que a Argentina e o Uruguai aumentam as suas exportações para, aproximadamente, 335 e 791 mil toneladas anuais, respectivamente.

Nos próximos cenários, Mercosul-UE e Mercosul-UE ampliada com a eliminação dos subsídios, os ganhos dos produtores do Mercosul e as perdas dos produtores europeus aumentam, enquanto os efeitos a terceiros mercados permanecem praticamente inalterados, quando comparados aos cenários anteriores. No cenário Mercosul-UE com a eliminação de subsídios, os produtores dos países do Mercosul são os maiores beneficiados, refletindo em acréscimos de $26,2 \%, 11,7 \%$ e $17,7 \%$ nos excedentes do produtor. Por outro lado, os produtores da UE 15 são os maiores prejudicados com a retirada das barreiras tarifárias e eliminação da concessão de subsídios tendo reduzido os seus excedentes dos produtores em 29,0\% em relação ao cenário-base, uma perda que alcança quase US\$ 597 milhões. Neste cenário, o Brasil amplia as exportações de 
arroz para a UE 15 em função da eliminação das tarifas e dos subsídios concedidos a produção pela UE 15. Neste caso, o Brasil passa a exportar, aproximadamente, 724 mil toneladas, enquanto a Argentina e o Uruguai exportam 367 e 802 mil toneladas anuais, respectivamente.

Com relação ao mercado de milho, observamos que os ganhos e perdas nos diversos cenários são praticamente nulos ou apenas pequenos nos cenários onde existe eliminação dos subsídios. A questão básica deve-se em parte à política comercial européia que restringe a entrada de milho em grão através de quotas-tarifárias, acrescido da concessão de subsídios aos seus produtores. Por outro lado, em todos os cenários são mantidos os subsídios americanos ao milho, permitindo que o produto americano tenha maior facilidade de ser exportado ao mercado europeu. Neste sentido, em nenhum cenário a eliminação das barreiras tarifárias mediante um acordo entre o Mercosul e a UE beneficia os países do Mercosul.

Nos cenários em que é considerada a eliminação dos subsídios por parte dos europeus, os maiores beneficiados pelo corte dos subsídios são os produtores norte-americanos. De qualquer maneira, os ganhos não são elevados em função da UE 15 manter as quotas-tarifárias. Com a eliminação dos subsídios por parte da UE 15, os agricultores europeus têm perdas em ambos os cenários, Mercosul-UE e Mercosul-UE ampliada, equivalentes a US\$183,6 e 288,1 milhões por ano, respectivamente. Já a região NAM, no cenário Mercosul-UE ampliada com a eliminação dos subsídios europeus, os produtores de milho têm ganhos da ordem de US\$ 73,8 milhões.

Com relação ao mercado da soja, não houve alterações em nenhum cenário alternativo simulado. Isto ocorre em função do Brasil e a Argentina já terem acesso ao mercado europeu, exportando soja em grão. Os países da UE 15, tradicionais importadores deste produto, não impõem barreiras tarifárias a importações de soja em grão, tampouco concedem aportes significativos de subsídios à produção de soja. Desta forma, quando simulamos o acordo entre os blocos não observamos variações na produção e nos excedentes do produtor. Pode-se esperar que maiores variações seriam observadas se fossem considerados outros cenários como, por exemplo, redução dos subsídios por parte dos EUA. No mercado da soja são aplicadas menores tarifas do que nos mercados dos 
demais produtos, contudo, o principal fator que contribui para distorcer o mercado internacional são os subsídios americanos, que aqui permaneceram mantidos em todos os cenários simulados.

Já no caso do mercado do trigo ocorreram mudanças em todos os cenários analisados. Para os cenários Mercosul-UE e Mercosul-UE ampliada mantendo os subsídios, as mudanças observadas foram devido à eliminação das barreiras tarifárias impostas pelos países do Mercosul (Argentina, Brasil e Uruguai), já que os países da UE 15 e da UE 10 não impõem barreiras tarifárias à importação de trigo de terceiros mercados. Para ambos os casos, a produção argentina, brasileira e uruguaia sofrem perdas equivalentes a US\$ 46,6, 14,3 e 0,78 milhões por ano, representando uma redução percentual do excedente do produtor na ordem de 4,0\%, 2,1\% e 2,5\%, respectivamente. Com a redução da produção de trigo nos países do Mercosul, os países da UE 15 são os principais beneficiados, obtendo ganhos de US\$ 28,6 milhões, equivalentes a um aumento de $0,2 \%$ no excedente do produtor. Os países da UE 10, novos integrantes do bloco, também são favorecidos com o acordo de livre comércio com os países do Mercosul, com ganhos aos produtores da ordem de US\$ 6 milhões.

No entanto, nos cenários Mercosul-UE e Mercosul-UE ampliada com eliminação dos subsídios, ocorrem mudanças significativas em relação ao cenário-base e aos demais cenários alternativos. Inicialmente, observamos que produtores dos países do Mercosul (Argentina, Brasil e Uruguai) continuam perdendo com ambos os acordos que envolvem os países da UE, contudo, nos cenários onde não são eliminados os subsídios às perdas são maiores. Desta forma, para ambos os cenários, a Argentina, o Brasil e o Uruguai perdem US\$ 43,5, 13,3 e 0,7 milhões. Nestes cenários, como são eliminados os subsídios europeus concedidos ao trigo, os produtores da UE 15 passam a sofrer perdas de US\$ 881,6 milhões, equivalentes a uma redução de 5,9\% nos excedentes do produtor. Por outro lado, os produtores da UE 10 obtém ganhos maiores que equivalem a US $\$ 14,1$ milhões, correspondendo a um aumento de $0,3 \%$ nos excedentes do produtor. Todavia, um dos maiores ganhadores neste cenário é a região da NAM, tradicionais exportadores de trigo que concedem subsídios à produção. Esta região passa a ganhar novos mercados em função das menores exportações de trigo por parte dos 
países da UE 15 e da Argentina. Os países do NAM têm acréscimos nos excedentes do produtor equivalente a US\$ 190 milhões, ou seja, um aumento de $2,7 \%$ no excedente do produtor.

De uma maneira geral, os maiores ganhos para os países do Mercosul ocorrem para o cenário Mercosul-UE com eliminação dos subsídios. Conjuntamente, os produtores da Argentina, do Brasil e do Uruguai obtêm ganhos totais (considerando todos os grãos) de US\$ 353,9 milhões. Destes países, o maior beneficiado é o Brasil que obtêm ganhos totais de US\$ 334,2 milhões. Os ganhos totais do Uruguai são de US\$ 36,3 milhões, enquanto a Argentina perde US\$16,6 milhões. Basicamente, a Argentina perde com este acordo comercial em função dos ganhos com a maior exportação de arroz não compensarem as perdas pela redução das exportações de trigo.

\section{Considerações finais}

Em termos gerais, os maiores ganhos para os produtores do Mercosul (aqui considerados os produtores da Argentina, Brasil e Uruguai) são obtidos pelo acordo Mercosul-UE com a eliminação dos subsídios, quando os ganhos conjuntos dos produtores de arroz superam as perdas dos produtores de trigo. Para os demais produtores, soja e milho, não houve mudanças significativas. Nesse cenário, os maiores benefícios foram garantidos porque foram eliminadas as barreiras comerciais entre os dois blocos, mas foram mantidas as barreiras com relação a outros países produtores e exportadores de arroz. Por outro lado, os produtores dos países da UE 15 apresentaram as maiores perdas em função da eliminação dos subsídios concedidos à produção de arroz, milho e trigo.

Considerando os resultados alcançados nos cenários alternativos onde existe a eliminação dos subsídios pela UE 15, observamos que os ganhos obtidos pelos produtores dos países do Mercosul e da UE 10 são muito pequenos quando comparados com as perdas dos produtores da UE 15. Por outro lado, observamos que os países da NAM (principalmente os EUA) por não eliminarem os subsídios à produção de grãos, são os maiores beneficiados com a eliminação dos subsídios por parte da UE 15. Estes resultados revelam a desvantagem da UE em negociar a eliminação de subsídios agrícolas através de acordos regionais de livre comércio. 
Assim, é importante que as negociações relativas aos subsídios concedidos pelos países desenvolvidos envolvam também os países da NAM, responsáveis por grande parte do aporte de subsídios à agricultura.

A contribuição empírica deste trabalho está na definição de que estes acordos comerciais proporcionam maiores benefícios aos produtores de arroz e maiores perdas aos produtores de trigo dos países do Mercosul. Salientamos que o caso dos produtores de soja no Brasil e na Argentina que já conquistaram seus espaços no mercado europeu e, portanto, novos acordos de livre comércio junto a este mercado não trariam vantagem adicional. Por último, o caso do milho, onde os países do Mercosul não obtêm ganhos em nenhum cenário em função da posição estratégica dos EUA (participante da NAM) junto ao mercado europeu, juntamente com os subsídios que os agricultores americanos recebem para a produção que ampliam a sua capacidade de exportação para terceiros mercados.

Por fim, cabe salientar que o trabalho tem limitações, como a disponibilidade de dados para a implementação do modelo e simplificações feitas, a partir de uma realidade complexa, para permitir a modelagem e simulação de cenários, avaliando os efeitos de políticas. Por outro lado, a contribuição metodológica deste trabalho permite obter os resultados mais próximos da realidade, a partir da elaboração de um modelo espacial que analisa a formação de preços em cada região e os impactos nos níveis de produção, consumo e fluxos comerciais. Um das principais vantagens deste método (PCM) está na inclusão das barreiras tarifárias e dos subsídios concedidos pelos países desenvolvidos aos produtores de grãos.

\section{Referências bibliográficas}

Alvim, A. M. Os impactos dos novos acordos de livre comércio sobre o mercado de arroz no Brasil: um modelo de alocação espacial e temporal. Porto Alegre: UFRGS, 2003. Tese (Doutorado em Economia) - Universidade Federal do Rio Grande do Sul, 2003.

Alvim, A. M. e Waquil, P. D. O problema de complementaridade mista: um modelo de alocação espacial aplicado ao setor agrícola. In: Santos, M. L. e Vieira, W. C. Métodos quantitativos em economia. Viçosa: UFV, 2004. Cap.6, p.161-190. 
Bishop, P. M., Nicholson, C. F., Pratt, J. E. Tariff-rate quotas: difficult to model or plain simple. Wellington: NZIER, 2001. (Paper presented at the annual conference of the New Zealand Agricultural and Resource Economics Society).

Nagurney, A., Nicholson, C. F., Bishop, P. M. Spatial price equilibrium models with discriminatory ad valorem tariffs: formulation and comparative computation using variational inequalities. In: Van den Bergh, J., Nijkamp, P., Rietveld, P. (Eds.). Recent advances in spatial equilibrium modelling: methodology and applications. New York: Springer, 1996.

Rutheford, T. F. Extension of GAMS for Complementarity problems arising in applied economic analysis. Journal of Economics Dynamics and Control, v.19, p. 1299-1324, 1995.

Samuelson, P. Spatial price equilibrium and linear programming. American Economic Review, v. 42, p. 283-303, 1952.

Sullivan, J. et al. 1989 global database for the Static World Policy Simulation (SWOPSIM) modeling framework. Washington, D.C.: USDA/ERS, 1992. (Staff Report AGES, 9215).

Waquil, P. D. Equilíbrio espacial: modelagem e aplicação ao setor de grãos em três cenários de integração regional. In: Montoya, M. A., Parré, J. L. (Eds.). $\mathrm{O}$ agronegócio brasileiro no final do século XX. Passo Fundo: UPF, 2000. v. 2.

Recebido em junho de 2005 e revisto em setembro de 2005 